\title{
Radiotherapy for large recurrent ameloblastoma of the mandible previously treated by surgery: A case report
}

\author{
Imane Mbarki ${ }^{1,2 *}$, Norosoa Randriamarosona ${ }^{1,2}$, Smaia Hajar Touimi ${ }^{1,2}$, Sanae Elmajjaoui ${ }^{1,2}$, Tayeb Kebdani ${ }^{1,2}$, Hanane Elkacemi ${ }^{1,2}$ and \\ Noureddine Benjaafar ${ }^{1,2}$ \\ ${ }^{1}$ Department of Radiotherapy, National Institute of Oncology, Rabat, Morocco \\ ${ }^{2}$ Mohammed V University of Rabat, Morocco
}

\begin{abstract}
Ameloblastoma is a benign odontogenic tumor. It is locally invasive and unlimited growth capacity, with a propensity for recurrence if not entirely excised. The therapeutic challenge in this type of tumors is to have an adequate resection with a wide margin of normal tissue but also a functional and aesthetically acceptable reconstruction of the residual defect. The role of radiotherapy is currently demonstrated in inoperable cases. We are reporting a case of a 45 years-old male patient with large ameloblastoma of the mandible recurrent 10 years after surgical resection. The patient benefited from exclusive radiotherapy at a dose of $60 \mathrm{~Gy}$.
\end{abstract}

Abbreviations: CT: computed tomography; Gy: gray; MRI: magnetic resonance imaging; VMAT: volumetric modulated arc therapy

\section{Introduction}

Odontogenic tumors are neoplasms that originate from the dental lamina and dental tissue performers. They start from the cells responsible for organogenesis [1]. They are very varied and very polymorphic. According to the tissue origin, they are classified as epithelial, mesodermal, or mixed. Ameloblastomas are the commonest tumors of epithelial origin and account for around $23 \%$ of odontogenic tumors [2].

Described for the first time by Cusack, et al. [3], ameloblastoma is known for its locally invasive and aggressive character. It has a strong tendency to recur which is well evidenced by its high recurrence rates [4]. The tumors are usually asymptomatic in their initial stages, they are only diagnosed later when the tumors reached a large size. The most common symptomatology is swelling, pain, and local discomfort $[2,5]$.

Treatment of mandibular ameloblastomas continues to be controversial. It can change with clinicoradiographic variant, anatomic localization, and clinical behavior of the tumor [6].

This article aims to present a case of a large recurrent mandibular ameloblastoma treated by radiotherapy, to discuss the diagnostic and therapeutic aspects of this tumor, as well as to evaluate the efficacy of radiotherapy.

\section{Case presentation}

A 44-year-old male patient, schizophrenic on treatment, operated on ten years ago for right mandibular ameloblastoma. Who has presented for a year a swelling over the right side of the lower jaw neglected by the patient and his entourage. There were no signs of difficulty in deglutition or breathing.

Physical examination revealed a large swelling measuring $6 \times 8 \mathrm{~cm}$ (Figure 1), anteriorly extending from the right angle of the mandible to

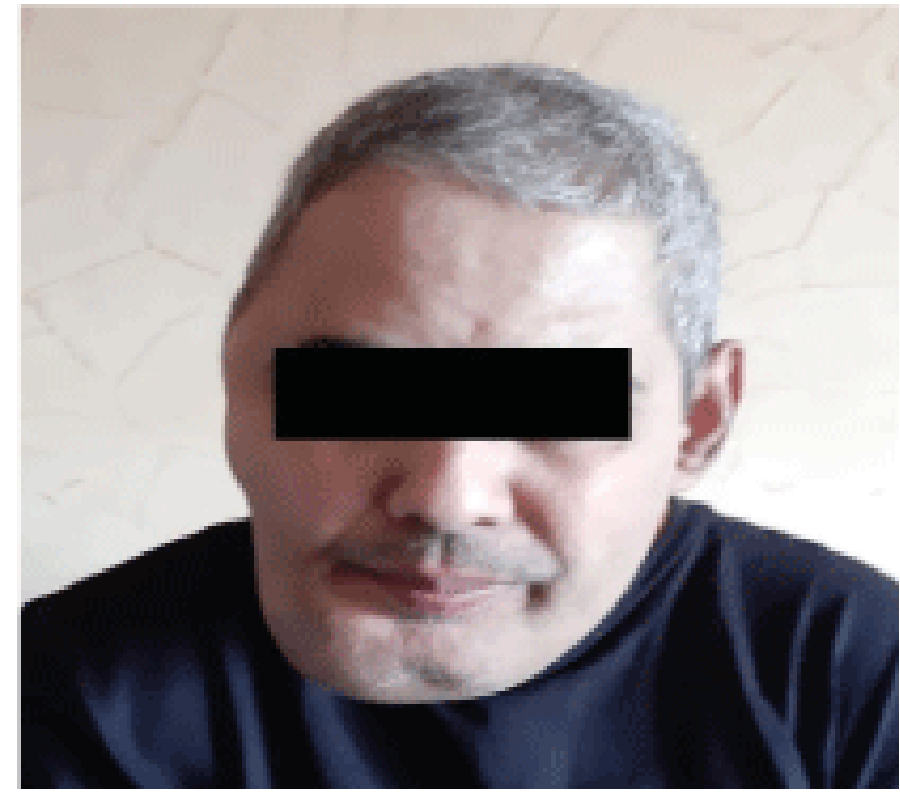

Figure 1. Swelling of the right mandibular region deforming the right hemiface

the right corner of the month, and superiorly from the external auditory canal, inferiorly into the right hyoid bone region of the neck, causing deformation and asymmetry of the face. The palpation of regional cervical lymph nodes doesn't reveal lymphadenopathy. The swelling was solid with normal overlying skin. Intra-oral examination revealed a gross tumor of the right mandibular buccal vestibule, overlying with intact mucosa. The oral opening was not limited. The tongue movement was normal.

${ }^{\star}$ Correspondence to: Imane MBARKI, Department of Radiation Oncology, National Institute of Oncology, Mohammed V University, Rabat, Morocco, E-mail: imanemb25@gmail.com

Received: April 30, 2021; Accepted: May 12, 2021; Published: May 19, 2021 


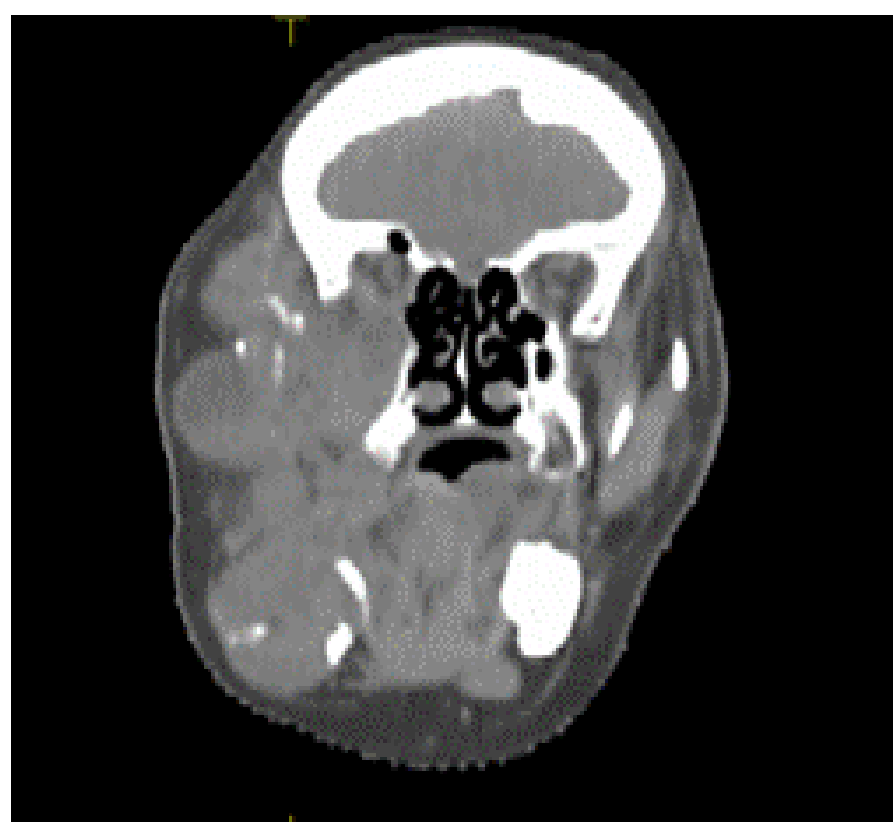

Figure 2. CT showing swelling in the right mandibular region deforming the right hemiface

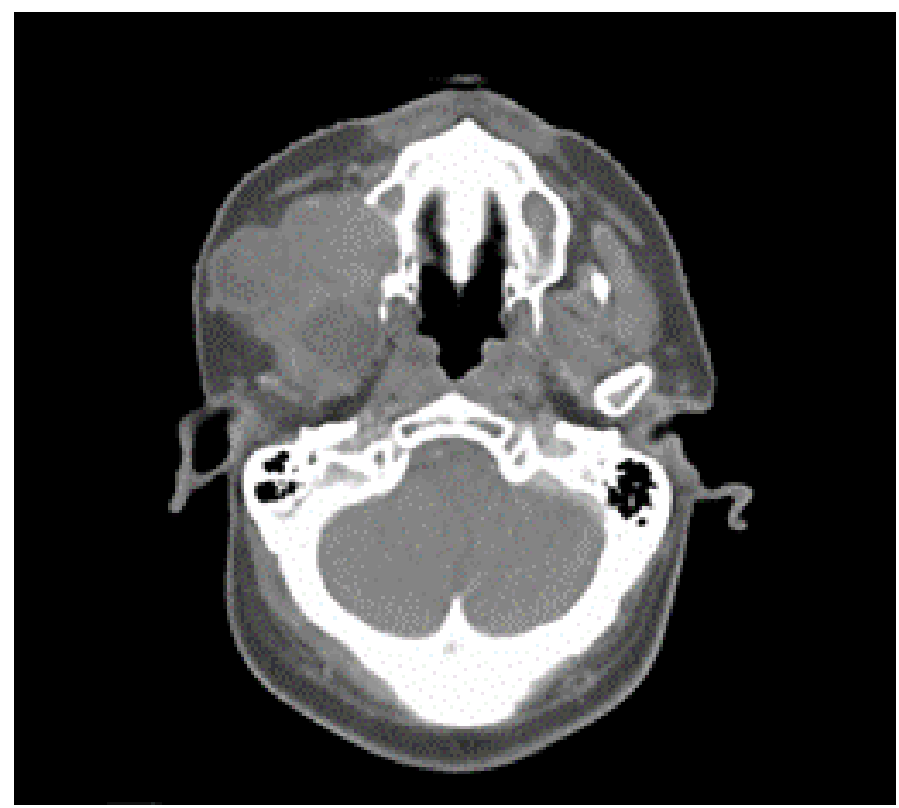

Figure 3. CT showing the tumor process leading to lysis of the external edge of the right maxillary sinus

A cervicofacial contrast CT scan of the mandible revealed a tumor process involving the right hemiface (Figure 2), responsible for horizontal and vertical branch lysis as well as temporomandibular joint and lysis of the external edge of the right maxillary sinus (Figure 3), with retro-orbital extension measuring $12 \times 8 \times 6,5 \mathrm{~cm}$ compatible with tumor recurrence. Although biopsy shows ameloblastoma with follicular type.

The patient received exclusive external radiotherapy with the VMAT technique, high-energy photons, at $60 \mathrm{~Gy}, 2 \mathrm{~Gy} /$ fraction, and 5 fractions/ week, in 49 days. The therapy was well tolerated by the patient. The radiotherapy has not been discontinued or interrupted because of relevant side effects. The evolution was marked by complete remission and the absence of recurrence after one year of post-therapeutic follow-up.

\section{Discussion}

Relatively common among odontogenic tumors but rare when considering maxillary tumors and cysts. Ameloblastoma has $1 \%$ of bone tumors [7] and 23\% of odontogenic tumors [2]. Most patients with ameloblastoma are between 30 to 60 years, the average age at the time of diagnosis varies from continent to continent estimated at approximately 42.4 and 30.4 years in Europe and Africa respectively [8]. Only $10-15 \%$ of ameloblastoma cases occur in the pediatric population but this can be as high as $25 \%$ in Africa and Asia [9]. It occurs with equal frequency in both sexes [10].

Ameloblastoma is located in the mandible in around $80 \%$ of the cases and the maxilla in the remaining 20\% [11-13]. In our case, the tumor was at the level of the mandible. The angular region represents the most frequent localization, with extension to the horizontal branch (70\%) then the para symphyseal and symphyseal regions (10\%) the tuberosity constitutes the preferred maxillary localization. More voluminous tumors may affect the adjacent soft tissues in an infiltrative manner, to the point of promoting erosion and reabsorption of the tooth roots [1].

Ameloblastoma is a benign but locally aggressive tumor with a high rate of recurrence if not resected adequately. They rarely show metastasis. There are available case reports listing metastasis [14,15]. Metastatic ameloblastoma refers to a lesion which metastasizes but the histology of both primary and metastatic tissues is benign.

Clinically, ameloblastoma appears as a slow-growing relatively painless tumor. Due to its locally aggressive growth characteristics, it can sometimes cause symptom as tooth mobility, tooth displacement, swelling, and paresthesia of the affected area [16]. Our patient had a gross facial asymmetry, no neurosensory deficits along the distribution of the trigeminal nerve were detected. Becelli, et al. [16] conducted a study carried out on 60 patients with mandibular ameloblastoma, and it was found that about half of them present typical symptom such as swelling of the affected regions (38.3\%), paresthesia of the innervated region of the mandibular nerve (13.3\%), and, alteration in dental occlusion (10\%).

Medical imaging is an essential step to establish the diagnosis of ameloblastoma. It uses conventional exams or even CT or MRI which allow for a thorough study. The use of plain film radiography is a good starting point. While it displays to some extent the multilocular pattern of ameloblastoma, it cannot demonstrate the three-dimensional structural expanse of ameloblastoma. CT shows an extensive tumor surrounded by a bone shell with a classical soap bubble appearance, irregular boundaries containing hypodense cystic areas, and isodense solid areas with a contrast of bone component after injection. 3D CT accurately shows the tumor margins and its relationship to the lower dental canal [17], which are vital for treatment planning. The use of MRI provides valuable details of the bone marrow and soft tissue components within and beyond the lesional margins of ameloblastomas. This is especially useful in delineating the extensions of maxillary ameloblastomas within the maxillary sinuses, orbits, and skull [18]. In our case, CT scan imaging revealed an extensive cystic tumor in the mandibular region.

Bilkay, et al. [19] in a retrospective analysis of 100 patients with mandibular ameloblastoma reported that a radiolucent lesion was found in $78 \%$ of the cases and $83 \%$ of them had cysts with well-defined borders.

However, even with a determined radiographic appearance, the definitive diagnosis of ameloblastoma should be sought by correlating this with histopathological examination of the lesion [20]. 

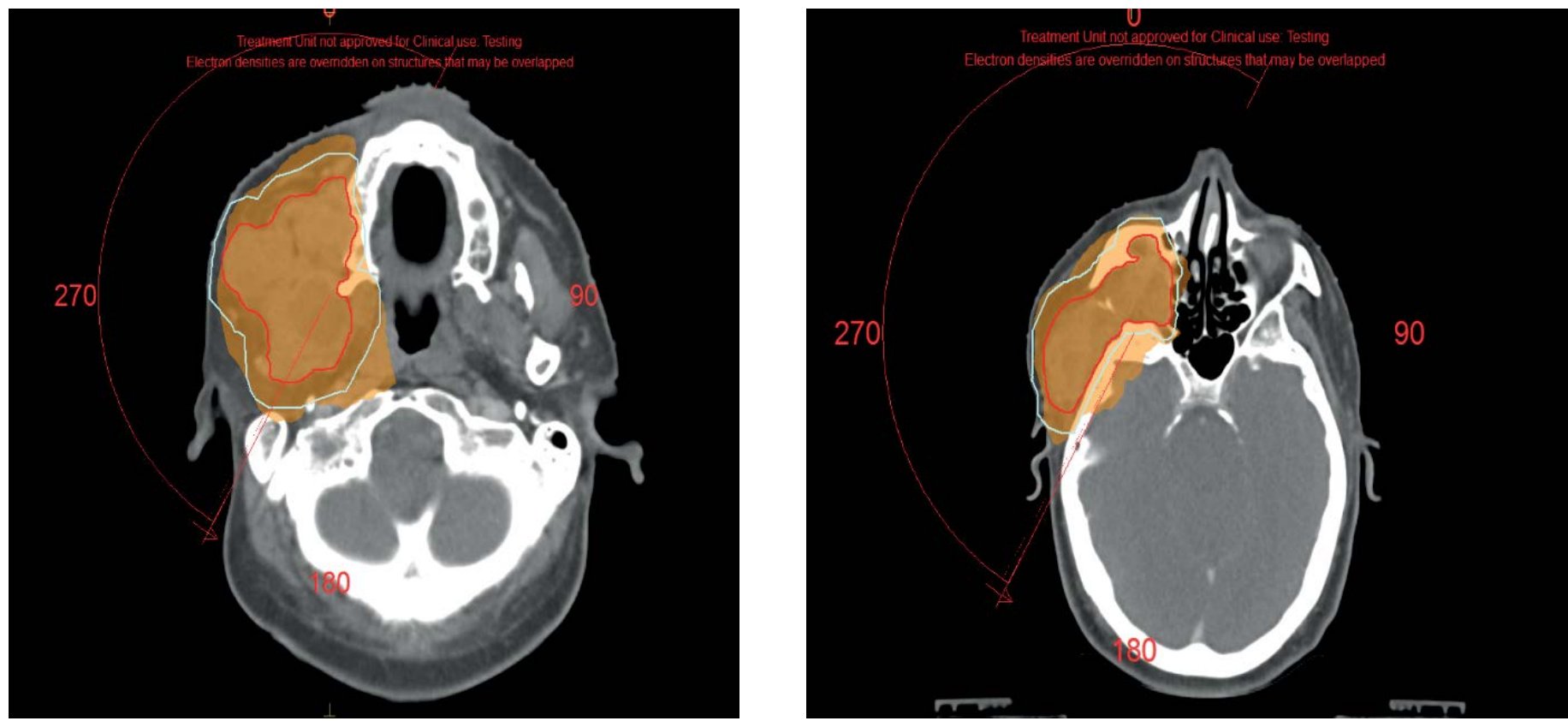

Figure 4. Image showing dose distribution by VMAT

Ameloblastoma is a benign tumor but is known for its recurrence. A study conducted by Henderson JM, et al. [21] suggests a local recurrence rate of $50 \%$ to $72 \%$ has been reported after initial therapy. Recurrence may be attributed to the method of treatment of the primary lesion, extent and, site of origin.

The treatment of choice of primary and recurrent ameloblastoma is radical or non-radical surgery. Surgical treatment implies total removal of the lesion, generally with a safety margin of one-two centimeters $[1,11]$, and is more indicated for a more aggressive lesion, such as in cases of multicystic ameloblastoma or even in unicystic cases with infiltrating characteristics. The conservative surgical treatment could be an enucleation, curettage, cryotherapy, or, marsupialization. This therapeutic approach provides the preservation of normal tissues of the patient, minimizes facial deformation, and, improves the patient's quality of life. But it is prone to a higher rate of recurrence, especially if it is an aggressive subtype [22]. Radical surgical treatment is customarily the treatment of choice for the aggressive subtype of primary and recurrent ameloblastoma. It involves en-bloc tumor resection with wide bone margin followed by immediate or delayed bone reconstruction of the surgical defect with tissue grafts and prosthetic rehabilitation [23]. The choice of surgical approach is difficult and, influenced by the risk of recurrence. However, the therapeutic decision must take into account several factors including the patient's age, the anatomical location of the tumor, its extension, the radiological appearance, and the need for regular follow-up of the patient. In our case, surgery was impossible due to the large size of the tumor recurrence which takes almost the entire right hemiface, and therefore a large surgical excision with negatives margins will be technically difficult.

A study by Ghandi, et al. [24] found an $80 \%$ recurrence rate after enucleation and curettage and less than $50 \%$ after radical treatment in 50 cases. Lau, et al. [25] made a study to determine the highest recurrence rate after different types of treatment of unicystic ameloblastoma: they reported a $3.9 \%$ recurrence after resection, 30.5\% after enucleation alone, and $18 \%$ after marsupialization with or without other treatment partners. In pediatric forms, conservative treatment is more easily indicated due to the imperatives bone growth but only in case of correct follow-up can be properly established. The 6 cases of pediatric ameloblastoma treated with Takahashi, et al. [26] showed satisfactory results within a bone deformation.

Most authors consider ameloblastoma to be radioresistant. Whereas in 1982 Reynolds wrote a major article on the effect of irradiation on ameloblastoma in which he discussed the basic principles of radiation therapy and concluded that radiotherapy has a place in locally advanced tumors or cases of surgery is refused [27]. A second important document is that of Atkinson in 1984, who published a series of 10 cases of ameloblastoma treated by radiotherapy, he concluded, based on his experience and the review of the literature that ameloblastomas are radiosensitive [28]. Since then, there are few published cases in the literature on the role of radiotherapy as a useful modality in the treatment of ameloblastomas [29-31]. Rastogi, et al, published in 2006 a case of locally advanced ameloblastoma of the mandible which responded well to external radiotherapy, within recurrence after two years of follow-up [32]. Different forms of radiation therapy have been used successfully for non-surgical management of ameloblastomas especially in patients medically unstable for surgery. These include helical tomotherapy, image-guided radiation therapy, intensity-modulated radiation therapy, and proton beam therapy. During treatment planning, it is imperative to balance the efficacy of radiotherapy with the risks of developing future life-threatening malignant transformations. Our patient benefited from exclusive radiotherapy using the VMAT technique, at a dose of $60 \mathrm{~Gy}$ in 2 Gy per fraction (Figure 4).

The risk of recurrence is greatest in the first three years but can occur much later, 15 to 30 years later. Our patient presented with recurrence 10 years after the initial surgery. It results in a clinical and radiological resumption of the tumor process in the same initial site. Adequate periodic clinical

and radiologic follow-up for at least ten years is highly essential. The rate and duration of surveillance depending on the quality of the 


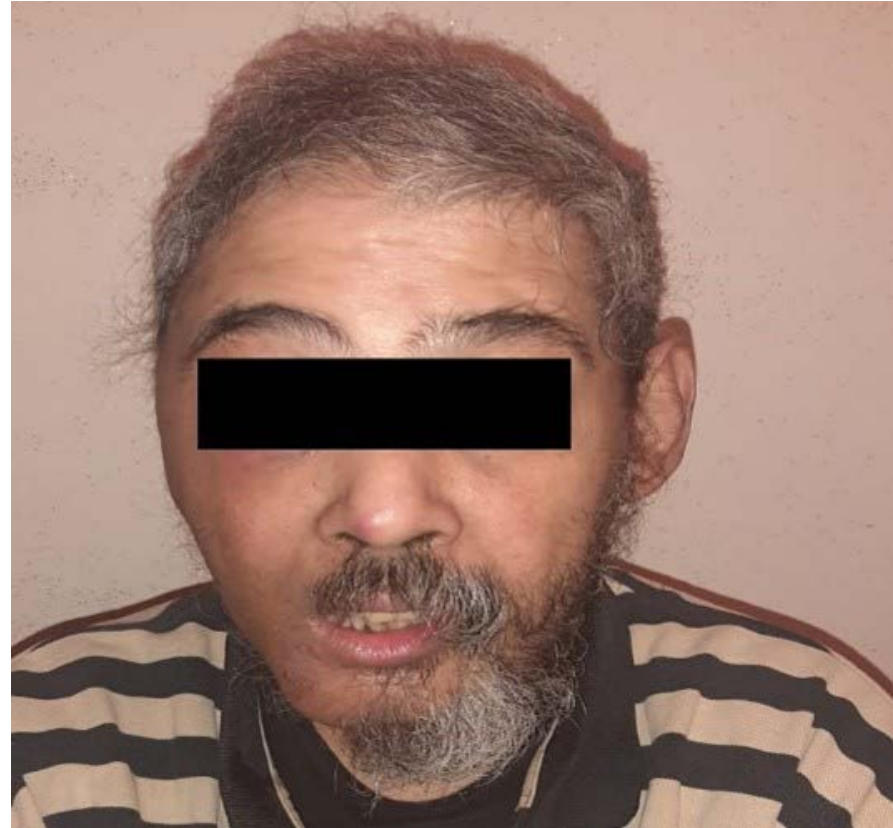

Figure 5. Image showing clinical response after treatment

surgical resection, of the histological subtype. In our case, no signs of clinical or radiological recurrence were detected 12 months after the end of treatment (Figure 5).

\section{Conclusion}

Ameloblastoma is an invasive tumor that, despite its benign character, sets the example of a tumor with major aggressive behavior, especially with its tendency to recur. It, therefore, requires a precise diagnosis, adequate management, and close follow-up. The treatment of ameloblastoma is a challenge. The goals are to minimize morbidity, improve survivorship, and the patient's quality of life. Radiotherapy finds its place in locally advanced forms or the event of a refusal of surgery. Radiotherapy with modulation of intensity is a real advance that allows delivering an adequate dose to the tumor while sparing the organs at risk.

\section{Acknowledgment}

We thank the Radiotherapy department and our radiotherapist colleagues at the National Institute of Oncology of Rabat who provided care and support for the patient.

\section{Disclosures}

The authors report no conflict of interest concerning the case in this paper.

\section{Consent}

Written informed consent was obtained from our patient for publication of this case report and accompanying images.

\section{References}

1. Sá AC, Zardo M, Paes Júnior AJ, Souza RP, Neme MP, et al. (2009) Ameloblastoma da mandíbula: relato de dois casos. Radiol Bras 37: 465-8.

2. Avelar RL, Antunes AA, Santos TS, Andrade ESS, Dourado E (2008) Tumores odontogênicos: estudo clínico-patológico de 238casos. Rev Bras Otorrinolaringol 74: 668-733.
3. Cusack JW (1827) Report of the amputations of the lower jaw. Dublin Hosp Rec 4: $1-38$.

4. Jordan RCK, Speight PM (2009) Current concepts of odontogenic tumours. Diagn Histopathol 15: 303-310.

5. Kim SG, Jang HS (2001) Ameloblastoma: a clinical, radiographic, and histopathologic analysis of 71 cases. Oral Surg Oral Med OralPathol 91: 649-653. [Crossref]

6. Sampson DE, Pogrel MA (1999) Management of mandibular ameloblastoma: the clinical basis for a treatment algorithm. J Oral Maxillofac Surg 57: 1074-1077.

7. Chomette G, Auriol M (1986) Histopathologie buccale cervico-faciale (pp.51-57) Masson, Paris.

8. Oomens MA, van der Waal I (2014) Epidemiology of ameloblastomas of the jaws; a report from the Netherlands. Med Oral Patol Oral Cir Bucal 19: e581-3.

9. Bansal S, Desai RS, Shirsat P, Prasad P, Karjodkar F (2015) The occurrence and pattern of ameloblastoma in children and adolescents: an Indian institutional study of 41 years and review of the literature. Int J Oral Maxillofac Surg 44: 725-731. [Crossref]

10. Mehlisch DR, Dahlin DC, Masson JK (1972) Ameloblastoma: A clinicopathologic report. J Oral Surg 30: 9-22.

11. Chagas JF, Toledo Júnior JI, Pascoal MBN, Pascoal MI, AquinoJL (2007) Ameloblastomas: aspectos clínicos eterapêuticos. Rev Bras Cir Cabeca Pescoco 36: 159-162.

12. Martinez CR, Barros RM, Orué NR, Oliveira JGP, Monteiro JCC (2008) Ameloblastoma: estudo clínico-histopatológico. Rev CirTraumatol Buco-Maxilo-Fac 8: 55-60.

13. Medeiros M, Porto GG, Laureano Filho JR, Portela L,Vasconcellos RH (2008) Ameloblastoma em mandíbula. Rev BrasOtorrinolaringol 74: 478.

14. Gunaratne DA, Coleman HG, Lim L, Morgan GJ (2015) Ameloblastic carcinoma. Am $J$ Case Rep 16: 415-419.

15. Benlyazid A, Lacroix-Triki M, Aziza R, Gomez-Brouchet A, Guichard M (2007) Ameloblastic carcinoma of the maxilla: case report and review of the literature. Oral Surg Oral Med Oral Pathol Oral Radiol Endod 104: e17-e24.

16. Becelli R, Carboni A, Cerulli G, Perugini M, Iannetti G (2002) Mandibular ameloblastoma: analysis of surgical treatment carried out in 60 patients between 1977 and 1998. J Craniofac Surg 13: 395-400.

17. Chala $\mathrm{S}$ (2000) Les améloblastomes de la mandibule a propos de 16 cas. Thèse de Médecine dentaire $n^{\circ} 33$, Rabat.

18. Fujita M, Matsuzaki H, Yanagi Y, Hara M, Katase N, et al. (2013) Diagnostic value of MRI for odontogenic tumours. Dentomaxillofac Radiol 42: 20120265. [Crossref]

19. Bilkay U, Tokat C, Helvaci E, Ozek C, Alper M (2004) Free fibula flap mandible reconstruction in benign mandibular lesions. J Craniofac Surg 15: 1002-1009.

20. Chagas JF, Toledo Júnior JI, Pascoal MBN, Pascoal MI, AquinoJL, et al (2007) Ameloblastomas: aspectos clínicos eterapêuticos. Rev Bras Cir Cabeca Pescoco 36: 159-162.

21. Henderson JM, Sonner JR, Ord RA (1999) Pulmonary metastasis of ameloblastoma: case report and review of literature. Oral Surg Oral Med Oral Pathol Oral Radiol Endod 88: 17 0-176.

22. Dandriyal R, Gupta A, Pant S, Baweja HH (2011) Surgical management of ameloblastoma: Conservative or radical approach. Natl J Maxillofac Surg 2: 22-27.

23. Shen YF, Rodriguez ED, Wei FC, Tsai CY, Chang YM (2015) Aesthetic and functional mandibular reconstruction with immediate dental implants in a free fibular flap and a low profile reconstruction plate: five-year follow-up. Annals of plastic surgery 74 : $442-6$

24. Ghandhi D, Ayoub AF, Pogrel MA, MacDonald G, Brocklebank LM (2006) Ameloblastoma: surgeon's dilemma. J Oral Maxillofac Surg 64 : 1010-1014.

25. Lau SL, Samman N (2006) Reccurence related to treatment modalities of unicystic ameloblastoma: a systematic review. Int J Oral Maxillofac Surg 35: 681-690.

26. Takahashi K, Miyauchi K, Sato K (1998) Treatment of ameloblastoma in children. Br J Oral Maxillofac Surg 36: 453e456.

27. Reynolds WR, Pacyniak J (1982) Ameloblastoma: radioresistant or radiosensitive. $J$ Mo Dent Assoc 62: 36-38.

28. Atkinson C, Harwood AR, Cummings BJ (1984) Ameloblastoma of the jaw: a reappraisal of the role of megavoltage irradiation. Cancer 53: 869-873. 
29. Sheinkopf DE, Friedman JM (1990) Radiotherapy in the management of recurrent ameloblastoma; a long-term follow-up of a case. $N$ Y State Dent J 56: 36-37.

30. Miyamoto CT, Brady LW, Markoe A, Salinger D (1991) Ameloblastoma of the jaw treatment with radiation therapy and a case report. Am J Clin Oncol 14: 225-230. [Crossref]
31. Anastassov GE, Rodriguez ED, Adamo AK, Friedman JM (1998) Case report: Aggressive ameloblastoma treated with radiotherapy, surgical ablation and reconstruction. J Am Dent Assoc 129: 84-87.

32. Rastogi M, Srivastava K, Bhatt MLB, Srivastava M, Sudhir S (2006) Giant ameloblastoma of jaw successfully treated by radiotherapy. Oral Oncology Extra 42: 22-25.

Copyright: $@ 2021$ Mbarki I. This is an open-access article distributed under the terms of the Creative Commons Attribution License, which permits unrestricted use, distribution, and reproduction in any medium, provided the original author and source are credited. 